\title{
Interruption of the HGF paracrine loop by NK4, an HGF antagonist, reduces VEGF expression of CT26 cells
}

\author{
TAKESHI KUBOTA $^{1 *}$, ATSUSHI MATSUMURA ${ }^{1 *}$, HIROAKI TAIYOH $^{1}$, YASUHITO IZUMIYA $^{1}$, \\ HITOSHI FUJIWARA ${ }^{1}$, KAZUMA OKAMOTO ${ }^{1}$, DAISUKE ICHIKAWA ${ }^{1}$, ATSUSHI SHIOZAKI ${ }^{1}$, \\ SHUHEI KOMATSU ${ }^{1}$, MASAYOSHI NAKANISHI ${ }^{1}$, YOSHIAKI KURIU ${ }^{1}$, YASUTOSHI MURAYAMA ${ }^{1}$, \\ HISASHI IKOMA ${ }^{1}$, TOSHIYA OCHIAI ${ }^{1}$, TAKAHIRO NAKAMURA ${ }^{2}$, KUNIO MATSUMOTO ${ }^{2}$, \\ TOSHIKAZU NAKAMURA ${ }^{3}$ and EIGO OTSUJI ${ }^{1}$ \\ ${ }^{1}$ Division of Digestive Surgery, Department of Surgery, Kyoto Prefectural University of Medicine, Kyoto; \\ ${ }^{2}$ Division of Tumor Dynamics and Regulation, Kanazawa University Cancer Research Institute, \\ Ishikawa; ${ }^{3}$ Kringle Pharma Joint Research Division for Regenerative Drug Discovery, \\ Center for Advanced Science and Innovation, Osaka University, Osaka, Japan
}

Received March 11, 2013; Accepted May 15, 2013

DOI: $10.3892 /$ or.2013.2509

\begin{abstract}
Hepatocyte growth factor (HGF), acting through the c-Met receptor, plays an important role in solid tumors. Various malignant cells utilize the biological actions of the $\mathrm{HGF} / \mathrm{c}-\mathrm{Met}$ pathway for their dissociative, invasive and metastatic behaviors. HGF also binds to the receptor expressed on endothelial cells that stimulates angiogenesis, a process critical to continued growth of solid tumors. It is known that HGF induces in vitro expression of vascular endothelial growth factor (VEGF), a key agonist of tumor angiogenesis. In the present study, we showed using in vitro co-culture system with fibroblasts that VEGF expression of CT26 cells was amplified through tumor-stromal interaction, i.e., the HGF paracrine loop. This action was inhibited by interruption of the HGF paracrine loop by gene transfer of NK4, an HGF antagonist. In in vivo experiments, CT26 tumor growth and angiogenesis were markedly enhanced by fibroblast co-inoculation, while the effect of fibroblasts was not observed in NK4-expressing CT26 cells. These findings suggest that NK4 exerted potent anti-angiogenic action via indirectly inhibiting VEGF expression of tumor cells in addition to direct effects on endothelial cells. Thus, the HGF/c-Met pathway may be a considerable candidate for molecular targeting strategy against tumor angiogenesis.
\end{abstract}

Correspondence to: Dr Takeshi Kubota, Division of Digestive Surgery, Department of Surgery, Kyoto Prefectural University of Medicine, 465 Kajii-cho, Kamigyo-ku, Kyoto 602-8566, Japan

E-mail: tkubot@koto.kpu-m.ac.jp

*Contributed equally

Key words: hepatocyte growth factor, NK4, vascular endothelial growth factor, tumor-stromal interaction, CT26

\section{Introduction}

Hepatocyte growth factor (HGF) and its receptor, c-Met, regulate a wide variety of cellular functions. HGF was originally identified and cloned as a mitogenic polypeptide for hepatocytes (1). Subsequent studies revealed that HGF-induced c-Met tyrosin kinase activation is involved in multiple biological effects, including mitogenic, motogenic, morphogenic and anti-apoptotic activities (2-5). In tumor tissues, however, various malignant cells express c-Met receptor and utilize the biological actions of HGF/c-Met pathway for their dissociative, invasive and metastatic behaviors (6-9). HGF also binds to the receptor expressed on endothelial cells that stimulates angiogenesis, a process critical to continued growth of solid tumors $(5,10)$.

In vivo tumor growth is enhanced by the coexistence of stromal fibroblasts. Host stromal-derived factor is a key molecule that enhances progressive potential of tumor cells. In several types of cancer, the HGF/c-Met pathway is regulated through the paracrine loop (11). Tumor cells secrete a variety of HGF-inducers, such as interleukin-1, basic fibroblast growth factor (bFGF), platelet-derived growth factor, transforming growth factor- $\alpha$ and prostaglandin E2, through which HGF production from stromal fibroblasts is upregulated (12). These observations suggest a mutual interaction between tumor cells and stromal fibroblasts; tumor cells secrete HGF-inducers for stromal cells, while stromal cells secrete HGF that may stimulate tumor growth and angiogenesis.

NK4, a product of proteolytic digestion of HGF, has been identified as a competitive antagonist for HGF and c-Met receptor and inhibits HGF-induced c-Met tyrosine phosphorylation (13). Furthermore, subsequent studies showed that NK4 has bifunctional actions to suppress not only $\mathrm{HGF} / \mathrm{c}-$ Met-dependent tumor progression and angiogenesis but also HGF/c Met-independent angiogenesis induced by bFGF and vascular endothelial growth factor (VEGF) $(14,15)$. In previous experiments using animal models, administra- 
tion of NK4 protein or NK4 gene therapy was demonstrated to suppress tumor invasion, metastasis, and angiogenesis, effectively transforming malignant tumors into benign-like dormant tumors. In this effect, anti-angiogenesis is considered to be predominant, especially in vivo $(16,17)$.

We previously demonstrated that $\mathrm{HGF} / \mathrm{c}-\mathrm{Met}$ pathway activation in CT26 tumor cells promoted HGF-inducers and subsequent stroma (fibroblast)-derived HGF secretion, resulting in amplifying HGF paracrine loop (18). Furthermore, some authors have shown that HGF stimulates endothelial cells directly and indirectly by facilitating expression of other angiogenic factors, represented by VEGF (19-21). Therefore, considering the angiogenic activity of HGF and tumor-stromal interaction, the mechanism of anti-angiogenesis by NK4 seems to be more complicated.

In the present study, we investigated the cooperation of HGF and VEGF in tumor-stromal interaction consisting of HGF paracrine loop using a co-culture system with CT26 tumor cells and fibroblasts and we described in vivo tumor anti-angiogenic activities of NK4 in detail.

\section{Materials and methods}

Cell lines and culture. CT26 is an undifferentiated colon adenocarcinoma cell line originally derived by intrarectal injections of N-nitroso-N-methylurethamine in a female BALB/c mouse. The genetic modification of CT26 to produce NK4 was previously described (18). The transfectant expressing the highest amount of NK4 was designated as CT26-NK4. Cells transfected with the neomycin-resistance gene (pSVneo) alone were used as a control (CT26-NEO). Primary mouse fibroblasts were obtained from dermal tissues in culture where fibroblasts initially proliferated outward from the tissues.

The CT26 transfectants and the fibroblasts were maintained in RPMI-1640 and MEM (both from Nacalai Tesque, Kyoto, Japan), respectively, supplemented with $100 \mathrm{IU} / \mathrm{ml}$ penicillin, $100 \mathrm{mg} / \mathrm{ml}$ streptomycin (Sigma, Welwyn Garden, $\mathrm{UK}$ ) and $10 \%$ heat-inactivated fetal bovine serum (FBS; JRH Biosciences, Lenexa, KS, USA) at $37^{\circ} \mathrm{C}$ in a humidified atmosphere containing $5 \% \mathrm{CO}_{2}$.

Determination of murine VEGF and HGF in a separate co-culture system. To evaluate regulation through soluble factors released by cancer cells and fibroblasts, each well of a 24-well plate was divided into two compartments using inner wells with $8 \mu \mathrm{m}$ pores (Cell Culture Insert; BD Falcon, Franklin Lakes, NJ, USA). Mouse fibroblasts were plated on 24-well culture plates at a density of $1 \times 10^{5}$ cells/well and were cultured for $24 \mathrm{~h}$. After replacing fresh media, tumor cells were seeded at $5 \times 10^{4}$ cells on each inner well and co-cultured for $24 \mathrm{~h}$. Cells were subsequently given fresh media with $0.2 \%$ FBS and were co-cultured for a further $32 \mathrm{~h}$. The cultured supernatants were collected every $8 \mathrm{~h}$ and the concentration of murine VEGF and HGF was determined by ELISA (VEGF; R\&D Systems, Minneapolis, MN, USA) (HGF; Institute of Immunology Co., Tokyo, Japan) according to the manufacturer's instructions. For time course analysis of VEGF or HGF secretion in the separate co-culture system, the cultured supernatants were collected 8, 16, 24 and $32 \mathrm{~h}$ after replacing fresh media with $0.2 \%$ FBS.
Real-time polymerase chain reaction analyses. Total RNA was isolated from tumor cells (the inner chamber) in the separate co-culture system using RNeasy Mini kit (Qiagen, Valencia, CA, USA) according to the manufacturer's instructions. The PCR primers used were: VEGF-A, 5'-CTGGAT ATGTTTGACTGCTGTGGA-3' (sense) and 5'-GTTTCTGG AAGTGAGCCAATGTG-3' (anti-sense). For normalization, the $18 \mathrm{~S}$ ribosomal protein served as the housekeeping gene. Rps18, 5'-TTCTGGCCAACGGTCTAGACAAC-3' (sense) and 5'-CCAGTGGTCTTGGTGTGCTGA-3' (anti-sense). Real-time RT-PCR was performed with a LightCycler1.5 (Roche, Basel, Switzerland) using SYBR-Green I (Qiagen). The RT-PCR protocol consisted of a $50^{\circ} \mathrm{C}$ reverse transcription step for $20 \mathrm{~min}$ and $95^{\circ} \mathrm{C}$ PCR initial activation step for 15 min followed by 40 cycles with a $94^{\circ} \mathrm{C}$ denaturation for $15 \mathrm{sec}, 60^{\circ} \mathrm{C}$ annealing for $30 \mathrm{sec}, 72^{\circ} \mathrm{C}$ extension for $30 \mathrm{sec}$. To confirm specific amplification, the PCR products were subjected to a melting curve analysis. The results of real-time RT-PCR were normalized with Rps18 and expressed as the relative value of control (CT26-NEO alone). Relative expression levels were calculated with the $\Delta \Delta \mathrm{Ct}$ method. Repeated experiments were performed for two or three times and similar results were obtained.

Animal experiments. Eight-week-old BALB/c female mice were purchased from Shimizu Laboratory Animal Center (Kyoto, Japan). All mice were maintained under specific-pathogen-free conditions. To generate in vivo tumors, $5 \times 10^{5}$ cells of CT26-NEO or CT26-NK4 with/without $1 \times 10^{6}$ cells of primary mouse fibroblasts co-cultured for $24 \mathrm{~h}$ were inoculated subcutaneously (s.c.) into syngeneic BALB/c mice in the right lower flank ( $\mathrm{n}=10$ for each group). Two perpendicular diameters of resulting tumors were measured every 2-3 days using a caliper. Tumor volumes were calculated using the formula, tumor volume $\left(\mathrm{mm}^{3}\right)=0.52 \mathrm{x}$ (width) $)^{2} \mathrm{x}$ (length). The investigation protocols were approved by the Ethics Committee of Kyoto Prefectural University of Medicine. The mice were sacrificed by excess administration of general anesthesia before the tumor weight exceeded $1 / 3$ of body weight.

Immunohistochemistry. BALB/c female mice were euthanized 14 days after the s.c. co-inoculation mentioned above. Tissues were fixed in $10 \%$ neutral-buffered formalin, embedded in paraffin. For staining of microvessels, tissue sections fixed in $10 \%$ formalin were subjected to immunostaining with a rat antibody against mouse CD31 (platelet endothelial cell adhesion molecule, or PECAM-1; Pharmingen, San Diego, CA, USA). The microvessel density was evaluated by counting CD31-positive vessels using a light microscope at 200 -fold magnification in $\geq 10$ randomly selected fields at the periphery of each section.

Statistical analysis. Statistical evaluation was performed with the two-tailed Student's t-test unless mentioned otherwise in the text. Differences with a P-value of $<0.05$ were considered statistically significant.

\section{Results}

VEGF and HGF secretion induced by a separate co-culture system with fibroblasts. To investigate whether mutual 

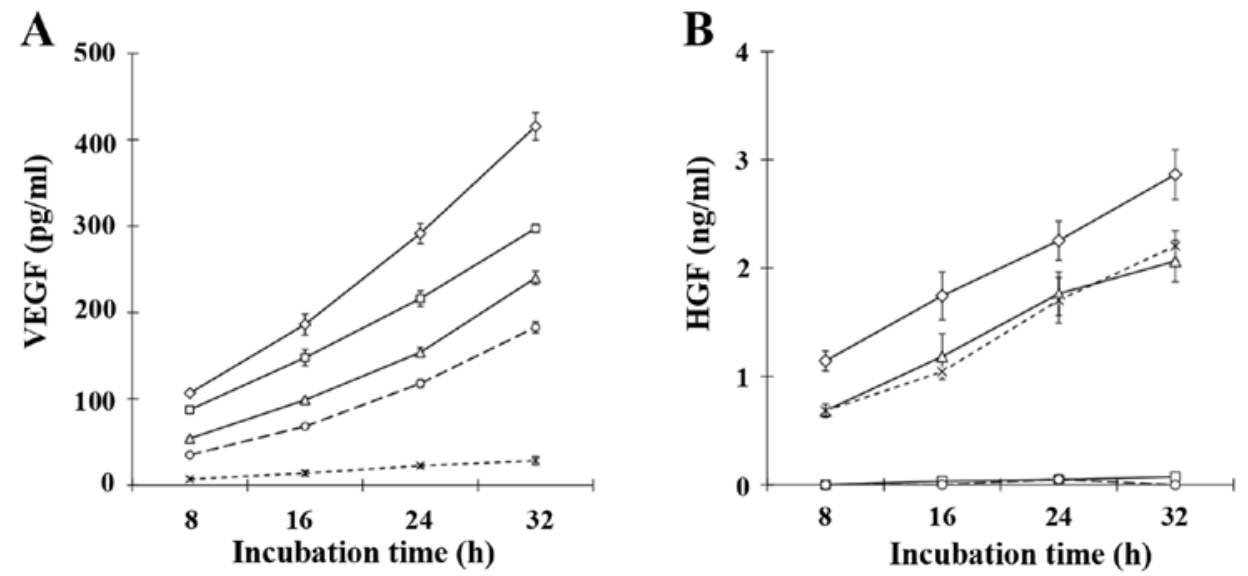

Figure 1. (A) Vascular endothelial growth factor (VEGF) and (B) hepatocyte growth factor (HGF) secretion of CT26 transfectants induced by the separate co-culture system with fibroblasts (F). Mouse fibroblasts were plated on 24-well culture plates and the CT26 transfectants were seeded in inner wells with $8 \mu \mathrm{m}$ pores, and then co-cultured for $24 \mathrm{~h}$. After replacing serum-starved media, cells were co-cultured for a further $32 \mathrm{~h}$. The cultured supernatants were collected every $8 \mathrm{~h}$ and the concentration of murine VEGF and HGF was determined by ELISA. $\diamond, C T 26-\mathrm{NEO}+\mathrm{F} ; \square, \mathrm{CT} 26-\mathrm{NEO}$ alone; $\triangle$, CT26-NK4+F; o, CT26-NK4 alone; $\mathrm{x}, \mathrm{F}$ alone. Bars represent mean $\pm \mathrm{SD}$.

tumor-stromal interaction induces VEGF expression, we determined VEGF concentration of separately co-cultured supernatants. As shown in Fig. 1A, fibroblasts alone secreted little VEGF, indicating that VEGF in co-cultured supernatants was derived from CT26 cells. VEGF secretion of CT26 transfectants increased time-dependently and was enhanced by separate co-culture with fibroblasts. The concentration of VEGF in CT26-NK4 was clearly lower than that in CT26-NEO. NK4 gene transfer strongly inhibited VEGF secretion of CT26 cells even in the co-culture system with fibroblasts. This suggested that soluble mediators, which were enhanced in the presence of fibroblasts, promoted VEGF secretion of CT26 cells through tumor-stromal interaction, and one of the soluble mediators seemed to be HGF, as VEGF secretion was suppressed by NK4, an HGF antagonist.

We then examined HGF concentration in the separate co-culture system. As shown in Fig. 1B, CT26 transfectants scarcely produced HGF, indicating that HGF in the co-culture system was derived from fibroblasts. The HGF production from fibroblasts increased time-dependently and was enhanced by co-culture with CT26-NEO. However, NK4 gene transfer suppressed HGF production down to the same level as that in fibroblasts alone. This result was similar to our previous study that demonstrated an obviously inductive effect when the conditioned media from CT26 transfectants were added to primary-cultured fibroblasts (18).

VEGF mRNA expression induced by a separate co-culture system with fibroblasts. We evaluated VEGF mRNA expression of CT26 transfectants in the co-culture system by real-time RT-PCR. VEGF mRNA of CT26-NEO in a co-culture system with fibroblasts was evidently higher than that of CT26-NEO alone. On the other hand, VEGF mRNA expression of CT26-NK4 was inhibited as compared to that of control. Although fibroblasts promoted VEGF mRNA expression of CT26-NK4, the change was smaller than that of CT26-NEO (Fig. 2). The changes of VEGF secretion in cultured supernatants were supported at the mRNA level of the tumor cells.

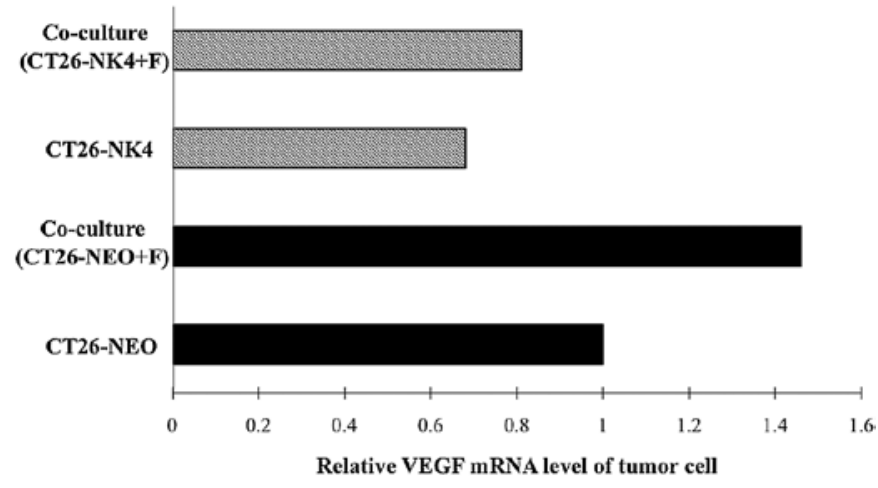

Figure 2. Relative vascular endothelial growth factor (VEGF) expression of CT26 transfectants induced by the separate co-culture system with fibroblasts (F). Total RNA isolated from tumor cells (the inner chamber) was subjected to real-time RT-PCR. The results of real-time RT-PCR were normalized with Rps18 and expressed as the relative value of control (CT26-NEO alone). Relative expression levels were calculated with the $\Delta \Delta \mathrm{Ct}$ method.

Tumor growth kinetics induced by co-inoculation with fibroblasts. Fig. 3 shows the growth curves of CT26-NEO and CT26-NK4 with/without fibroblast co-inoculation. CT26-NEO tumor growth was markedly enhanced by fibroblasts, while the effect of fibroblast co-inoculation was not observed in CT26-NK4. This result revealed that NK4 gene transfer blocked the enhancing effect of fibroblasts on in vivo CT26 s.c. tumor growth.

Implanted tumor vascularity induced by co -inoculation with fibroblasts. We next examined whether co-inoculation with fibroblasts would promote angiogenesis of homografts. Similar to our previous study, the microvessel density of CT26-NK4 homografts was evidently lower than that of CT26-NEO. Co-inoculation of CT26-NEO with fibroblasts showed a significant increase in microvessel density as compared with CT26-NEO cells alone, however, this effect was not observed in CT26-NK4 (Fig. 4). Thus, NK4 gene transfer completely canceled the enhancing effect of co-inoculation with fibroblasts on CT26 tumor vascularity. 


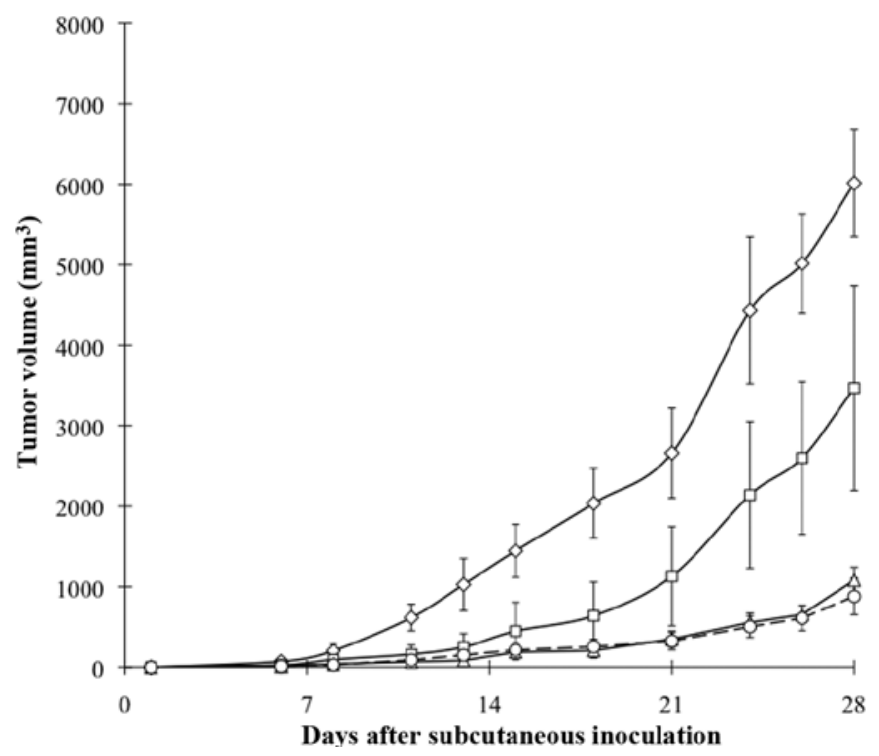

Figure 3. Subcutaneous tumor growth kinetics of CT26 transfectants co-injected with co-cultured fibroblasts (F). Cells $\left(5 \times 10^{5}\right)$ with/without $1 \times 10^{6}$ cells of mouse fibroblasts co-cultured for $24 \mathrm{~h}$ were inoculated in the right lower flank of syngeneic BALB/c mice ( $\mathrm{n}=10$ for each group). Two perpendicular diameters of resulting tumors were measured every $2-3$ days. Tumor volumes were calculated using the formula, tumor volume $\left(\mathrm{mm}^{3}\right)=0.52 \mathrm{x}(\text { width })^{2} \mathrm{x}($ length) . $\diamond, \mathrm{CT} 26-\mathrm{NEO}+\mathrm{F} ; \square, \mathrm{CT} 26-\mathrm{NEO}$ alone; $\triangle, \mathrm{CT} 26-\mathrm{NK} 4+\mathrm{F} ; \circ, \mathrm{CT} 26-\mathrm{NK} 4$ alone. Bars represent mean $\pm \mathrm{SD}$.

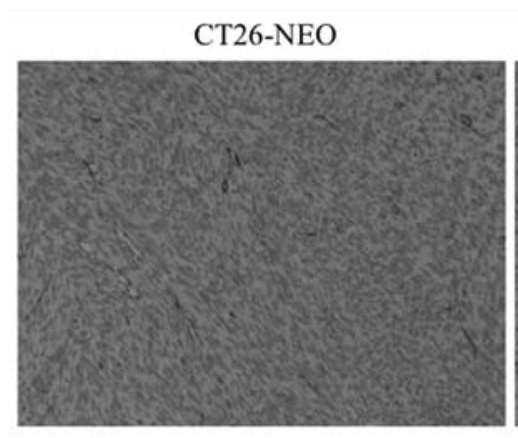

CT26-NK4

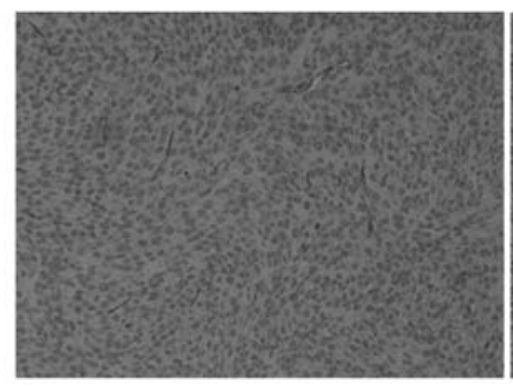

CT26-NEO + F

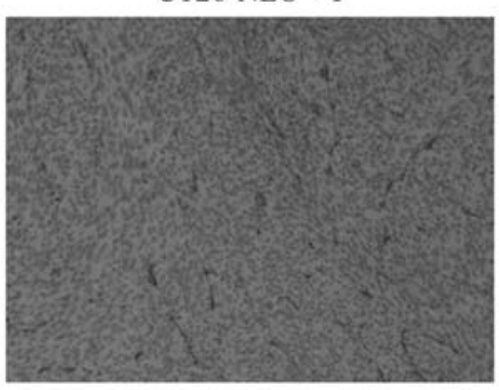

CT26-NK4

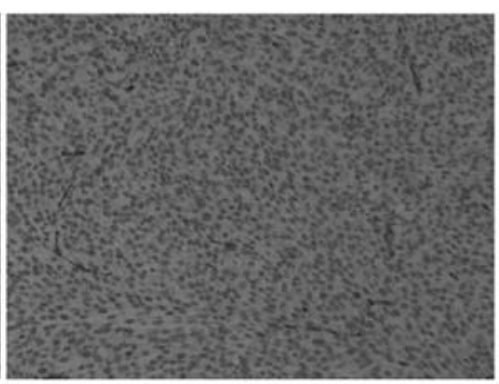

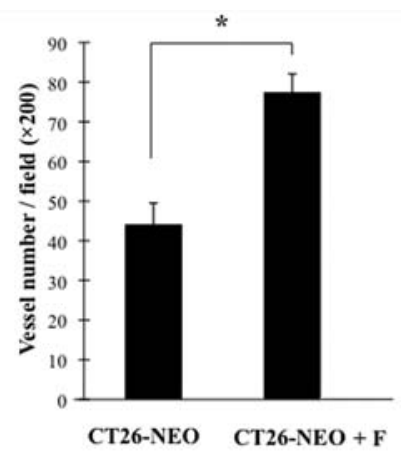

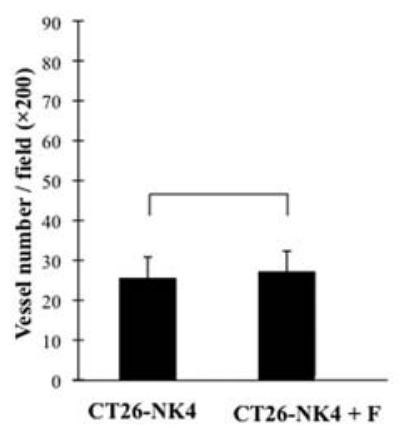

Figure 4. Subcutaneous tumor angiogenesis of CT26 transfectants co-injected with co-cultured fibroblasts (F). For microvessels, tissue sections obtained 14 days after subcutaneous co-inoculation were subjected to immunostaining with a CD31 antibody. The microvessel density was evaluated by counting CD31-positive vessels using a light microscope at 200 -fold magnification in $\geq 10$ randomly selected fields at the periphery of each section. Bars represent mean \pm SD. ${ }^{*} \mathrm{P}<0.001$.

\section{Discussion}

In the present study, we found that tumor angiogenesis involved co-operation between HGF and VEGF in CT26 tumor cells and tumor-stromal interaction consisting of the HGF paracrine loop intricately. Furthermore, we gained understanding of the importance of fibroblasts in tumor angiogenesis. Recent studies have shown that interactions between tumor and stromal cells create a unique microenvironment that is essential for tumor growth $(22,23)$. Tumor stroma contains several types, such as activated fibroblasts, endothelial cells, and inflammatory cells including macrophages. It has become clear that activated fibroblasts in cancer stroma are prominent modifiers of tumor progression.

It has been reported that normal fibroblasts inhibit cancer progression (24). The transdifferentiation of fibroblasts into cancer-associated fibroblasts is modulated by cancer cell-derived cytokines, such as transforming growth 


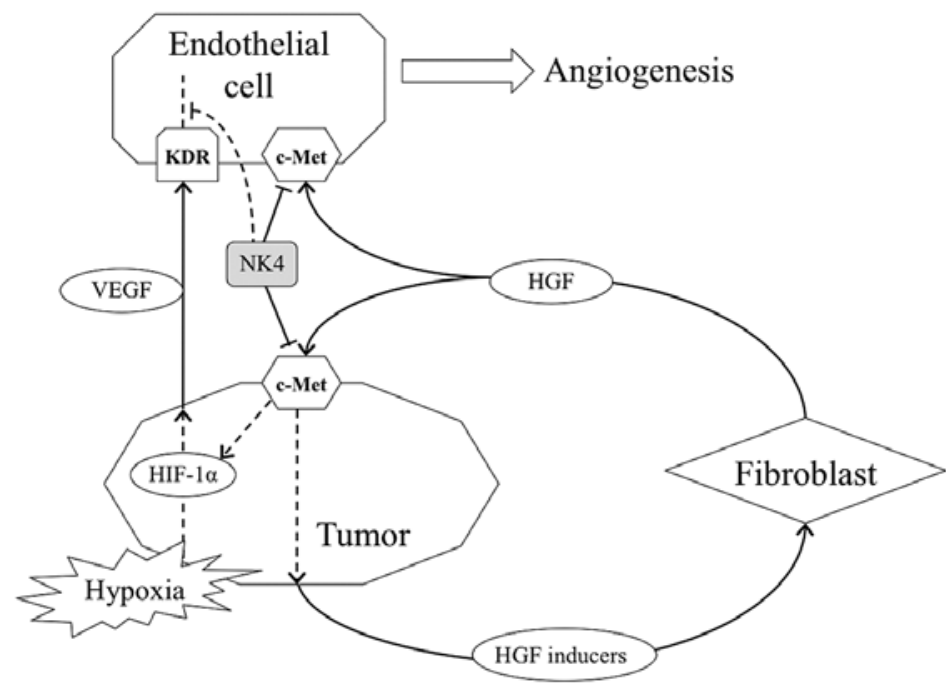

Figure 5. Schematic representation of angiogenesis involving tumor-stromal (fibroblast) interaction. Tumor cells facilitate fibroblasts to secrete hepatocyte growth factor (HGF) by producing HGF inducers and utilize HGF by themselves to progress. This process mediated by HGF paracrine loop is considered to amplify like a malignant cycle. HGF directly acts on endothelial cells to induce angiogenesis. Furthermore, HGF induces vascular endothelial growth factor (VEGF) expression of tumor cells through intracellular signaling downstream of HGF/c-Met. On the other hand, interpretation of HGF paracrine loop by NK4 reduces HGF and VEGF expression, resulting in potent anti-angiogenesis.

factor- $\beta$ (TGF- $\beta$ ), platelet-derived growth factor (PDGF), and bFGF (25-27), which have been identified as HGF inducers $(12,28)$. Therefore, we used the fibroblasts activated by pre co-culture with CT26 cells in both our in vitro and in vivo studies. In the in vitro separate co-culture system, fibroblast-derived HGF secretion was verified to increase time-dependently as compared with fibroblast alone. Our previous study revealed that the HGF/c-Met pathway activation promoted secretion of HGF inducers and subsequent fibroblast-derived HGF. Collectively, the results of our in vitro studies may demonstrate the process of CT26 tumor progression mediated by HGF paracrine loop that is amplified like a malignant cycle. On the other hand, HGF promoted by paracrine loop amplification naturally acts not only on tumor cells but also on endothelial cells and induces angiogenesis. In fact, serum HGF level and/or c-Met expression on tumor cells are reported to correlate tumor vascularity with clinical prognosis $(29,30)$.

Similar to fibroblast-derived HGF, tumor-derived VEGF was also promoted in the separate co-culture system with fibroblasts. $\mathrm{HGF} / \mathrm{c}-\mathrm{Met}$ pathway activation is reported to induce the VEGF expression in cancer cells in addition to stimulating endothelial cells to proliferate and migrate, inducing blood formation $(21,31)$. We also previously showed in an in vitro study using the CT26 transfectants that VEGF expression was induced by HGF and this action was effectively inhibited by anti-HGF neutralizing antibody and HGF antagonist NK4. Furthermore, we have revealed that tumor-derived VEGF expression also decreased in in vivo CT26 tumor and this action involved HIF-1 $\alpha$ synthesis through $\mathrm{HGF} / \mathrm{c}-$ Met pathway downstream; PI3K, MAPK, STAT3 signaling (32). From these findings, HGF amplified by malignant cycle of the paracrine loop possibly stimulates endothelial cells directly and indirectly via increased secretion of tumor-derived VEGF, resulting in accelerating tumor angiogenesis. Therefore, interruption of the malignant cycle may hold the key to exert anti-angiogenesis for VEGFexpressing and c-Met positive cancer. In in vivo experiments of the present study, NK4 gene transfer completely blocked angiogenesis and tumor growth which were enhanced by co-inoculation with fibroblasts.

Since angiogenesis is critical for tumor growth, increased angiogenesis coincides with increased tumor cell entry into blood circulation and thus facilitates metastasis (33). Therapeutic approaches using angiogenesis inhibitors have received much attention. NK4, an HGF antagonist, is also known to have anti-angiogenic activity, which is independent of its activity as an HGF antagonist (15). Accumulating evidence has shown that NK4 suppresses primary tumor growth predominantly through inhibition of tumor angiogenesis. Our results showed that fibroblast-derived HGF and tumor-derived VEGF, induced by co-culture of CT26 cells with fibroblasts, were inhibited by NK4 gene transfer. This was due to interruption of the malignant cycle of the HGF paracrine loop by blockade of the HGF/c-Met pathway; that is, the activity of NK4 as an HGF antagonist. Furthermore, the findings in our in vivo study are consistent with previous studies. Thus, antiangiogenesis strategy by NK4 is expected to exert additional effects on c-Met positive tumor grown up depending on HGF paracrine loop through intricate tumor-stromal interaction (Fig. 5).

In conclusion, we have demonstrated that the HGF/c-Met pathway regulated VEGF expression of CT26 cells through the HGF paracrine loop. For anti-tumor strategy, the interruption of HGF paracrine loop by NK4 possibly exerts potent anti-angiogenic activity via inhibition of tumor-derived VEGF expression in addition to the previously reported mechanisms, such as suppression of endothelial cell proliferation by antagonizing HGF/c-Met pathway or blockade of intracellular signaling downstream of VEGF and bFGF. Therefore, the HGF/c-Met pathway may be a significant candidate for molecular targeting strategy against tumor angiogenesis. 


\section{References}

1. Nakamura T, Nishizawa T, Hagiya M, Seki T, Shimonishi M, Sugimura A, Tashiro K and Shimizu S: Molecular cloning and expression of human hepatocyte growth factor. Nature 342: 440-443, 1989

2. Matsumoto K, Okazaki H and Nakamura T: Up-regulation of hepatocyte growth factor gene expression by interleukin-1 in human skin fibroblasts. Biochem Biophys Res Commun 188 235-243, 1992

3. Brinkmann V, Foroutan H, Sachs M, Weidner KM and Birchmeier W: Hepatocyte growth factor/scatter factor induces a variety of tissue-specific morphogenic programs in epithelial cells. J Cell Biol 131: 1573-1586, 1995.

4. Schmidt C, Bladt F, Goedecke S, Brinkmann V, Zschiesche W, Sharpe M, Gherardi E and Birchmeier C: Scatter factor/hepatocyte growth factor is essential for liver development. Nature 373: 699-702, 1995

5. Bussolino F, Di Renzo MF, Ziche M, Bocchietto E, Olivero M, Naldini L, Gaudino G, Tamagnone L, Coffer A and Comoglio PM: Hepatocyte growth factor is a potent angiogenic factor which stimulates endothelial cell motility and growth. J Cell Biol 119: 629-641, 1992

6. Di Renzo MF, Olivero M, Giacomini A, Porte H, Chastre E, Mirossay L, Nordlinger B, Bretti S, Bottardi S, Giordano S, Plebani M, Gespach C and Comoglio PM: Overexpression and amplification of the met/HGF receptor gene during the progression of colorectal cancer. Clin Cancer Res 1: 147-154, 1995.

7. Matsumoto $\mathrm{K}$ and Nakamura T: Emerging multipotent aspects of hepatocyte growth factor. J Biochem 119: 591-600, 1996.

8. Birchmeier C, Birchmeier W, Gherardi E and Vande Woude GF: Met, metastasis, motility and more. Nat Rev Mol Cell Biol 4: 915-925, 2003

9. Miller CT, Lin L, Casper AM, Lim J, Thomas DG, Orringer MB, Chang AC, Chambers AF, Giordano TJ, Glover TW and Beer DG: Genomic amplification of MET with boundaries within fragile site FRA7G and upregulation of MET pathways in esophageal adenocarcinoma. Oncogene 25: 409-418, 2006.

10. Grant DS, Kleinman HK, Goldberg ID, Bhargava MM, Nickoloff BJ, Kinsella JL, Polverini P and Rosen EM: Scatter factor induces blood vessel formation in vivo. Proc Natl Acad Sci USA 90: 1937-1941, 1993.

11. Di Renzo MF, Poulsom R, Olivero M, Comoglio PM and Lemoine NR: Expression of the Met/hepatocyte growth factor receptor in human pancreatic cancer. Cancer Res 55: 1129-1138, 1995.

12. Nakamura T, Matsumoto $\mathrm{K}$, Kiritoshi A, Tano $\mathrm{Y}$ and Nakamura T: Induction of hepatocyte growth factor in fibroblasts by tumor-derived factors affects invasive growth of tumor cells: in vitro analysis of tumor-stromal interactions. Cancer Res 57: 3305-3313, 1997.

13. Date K, Matsumoto K, Shimura H, Tanaka M and Nakamura T: HGF/NK4 is a specific antagonist for pleiotrophic actions of hepatocyte growth factor. FEBS Lett 420: 1-6, 1997.

14. Kuba K, Matsumoto K, Date K, Shimura H, Tanaka M and Nakamura T: HGF/NK4, a four-kringle antagonist of hepatocyte growth factor, is an angiogenesis inhibitor that suppresses tumor growth and metastasis in mice. Cancer Res 60: 6737-6743, 2000

15. Matsumoto $\mathrm{K}$ and Nakamura T: Mechanisms and significance of bifunctional NK4 in cancer treatment. Biochem Biophys Res Commun 333: 316-327, 2005.

16. Saimura M,Nagai E, Mizumoto K, Maehara N, Minamishima YA, Katano M, Matsumoto K, Nakamura T and Tanaka M: Tumor suppression through angiogenesis inhibition by SUIT-2 pancreatic cancer cells genetically engineered to secrete NK4. Clin Cancer Res 8: 3243-3249, 2002.

17. Tomioka D, Maehara N, Kuba K, Mizumoto K, Tanaka M, Matsumoto K and Nakamura T: Inhibition of growth, invasion, and metastasis of human pancreatic carcinoma cells by NK4 in an orthotopic mouse model. Cancer Res 61: 7518-7524, 2001.
18. Kubota T, Fujiwara H, Amaike H, Takashima K, Inada S, Atsuji K, Yoshimura M, Matsumoto K, Nakamura T and Yamagishi H: Reduced HGF expression in subcutaneous CT26 tumor genetically modified to secrete NK4 and its possible relation with antitumor effects. Cancer Sci 95: 321-327, 2004.

19. Gerritsen ME, Tomlinson JE, Zlot C, Ziman M and Hwang S: Using gene expression profiling to identify the molecular basis of the synergistic actions of hepatocyte growth factor and vascular endothelial growth factor in human endothelial cells. Br J Pharmacol 140: 595-610, 2003.

20. Wojta J, Kaun C, Breuss JM, Koshelnick Y, Beckmann R, Hattey E, Mildner M, Weninger W, Nakamura T, Tschachler E and Binder BR: Hepatocyte growth factor increases expression of vascular endothelial growth factor and plasminogen activator inhibitor-1 in human keratinocytes and the vascular endothelial growth factor receptor flk-1 in human endothelial cells. Lab Invest 79: 427-438, 1999.

21. Dong G, Chen Z, Li ZY, Yeh NT, Bancroft CC and Van Waes C: Hepatocyte growth factor/scatter factor-induced activation of MEK and PI3K signal pathways contributes to expression of proangiogenic cytokines interleukin- 8 and vascular endothelial growth factor in head and neck squamous cell carcinoma. Cancer Res 61: 5911-5918, 2001.

22. Mantovani A, Allavena P, Sica A and Balkwill F: Cancer-related inflammation. Nature 454: 436-444, 2008.

23. Whiteside TL: The tumor microenvironment and its role in promoting tumor growth. Oncogene 27: 5904-5912, 2008.

24. Kuperwasser C, Chavarria T, Wu M, Magrane G, Gray JW, Carey L, Richardson A and Weinberg RA: Reconstruction of functionally normal and malignant human breast tissues in mice. Proc Natl Acad Sci USA 101: 4966-4971, 2004.

25. De Wever O and Mareel M: Role of tissue stroma in cancer cell invasion. J Pathol 200: 429-447, 2003.

26. Pietras K, Sjöblom T, Rubin K, Heldin $\mathrm{CH}$ and Ostman A: PDGF receptors as cancer drug targets. Cancer Cell 3: 439-443, 2003.

27. Kitadai Y: Cancer-stromal cell interaction and tumor angiogenesis in gastric cancer. Cancer Microenviron 3: 109-116, 2010.

28. Matsumoto K, Date K, Shimura H and Nakamura T: Acquisition of invasive phenotype in gallbladder cancer cells via mutual interaction of stromal fibroblasts and cancer cells as mediated by hepatocyte growth factor. Jpn J Cancer Res 87: 702-710, 1996.

29. Ren Y, Cao B, Law S, Xie Y, Lee PY, Cheung L, Chen Y, Huang X, Chan HM, Zhao P, Luk J, Vande Woude G and Wong J: Hepatocyte growth factor promotes cancer cell migration and angiogenic factors expression: a prognostic marker of human esophageal squamous cell carcinomas. Clin Cancer Res 11: 6190-6197, 2005

30. Kaposi-Novak P, Lee JS, Gòmez-Quiroz L, Coulouarn C, Factor VM and Thorgeirsson SS: Met-regulated expression signature defines a subset of human hepatocellular carcinomas with poor prognosis and aggressive phenotype. J Clin Invest 116: $1582-1595,2006$

31. Moriyama T, Kataoka H, Hamasuna R, Yokogami K, Uehara H, Kawano H, Goya T, Tsubouchi H, Koono M and Wakisaka S: Up-regulation of vascular endothelial growth factor induced by hepatocyte growth factor/scatter factor stimulation in human glioma cells. Biochem Biophys Res Commun 249: 73-77, 1998.

32. Matsumura A, Kubota T, Taiyoh H, Fujiwara H, Okamoto K, Ichikawa D, Shiozaki A, Komatsu S, Nakanishi M, Kuriu Y, Murayama Y, Ikoma H, Ochiai T, Kokuba Y, Nakamura T, Matsumoto K and Otsuji E: HGF regulates VEGF expression via the c-Met receptor downstream pathways, PI3K/Akt, MAPK and STAT3, in CT26 murine cells. Int J Oncol 42: 535-542, 2013.

33. Hanahan D and Folkman J: Patterns and emerging mechanisms of the angiogenic switch during tumorigenesis. Cell 86: 353-364, 1996. 